\title{
Direitos humanos e violência nas escolas: desafios do trabalho em rede
}

\author{
Ana Maria Eyngi \\ Pontifícia Universidade Católica do Paraná, Brasil
}

\begin{abstract}
Resumo
A garantia de direitos constitui-se na principal via para a superação das violências nas escolas. Tal proposição supõe trabalho em rede e requer esforços conjuntos. Embora a escola se constitua em espaço estratégico na efetivação da rede, as ações protagonizadas a partir da e na escola são ainda frágeis. Essa constatação motiva o estudo aqui relatado, que investiga as percepções de gestores escolares, professores, pais e conselheiros tutelares sobre a rede de proteção na garantia de direitos de crianças e adolescentes. A apresentação e a discussão dos dados empíricos são analisadas abordando as tensões entre violências e garantia de direitos nas escolas e a rede de proteção na garantia de direitos. Os resultados do diagnóstico, apresentado nesse estudo, permitem esboçar ações estratégicas, no fortalecimento dos sujeitos para as múltiplas configurações que o trabalho de proteção e garantia de direitos demanda a partir da escola.
\end{abstract}

Palavras-chave

Políticas Educacionais; Violências nas escolas; Garantia de direitos; Rede de proteção de direitos

\section{Introdução}

A garantia de direitos constitui-se na via para atenuar e, quiçá, superar as violências nas escolas. Esse desafio, amplo e complexo, lança-se para os diversos sujeitos e setores da escola e da comunidade. 
Os Direitos Humanos "emergem gradualmente das lutas que o homem trava por sua própria emancipação e das transformações das condições de vida que essas lutas produzem" (Bobbio, 2004, p. 51). A proposição de Bobbio considera o movimento histórico na configuração do que hoje entendemos e temos como políticas de direitos humanos.

(...) a história dos direitos humanos deve ser lida (...) como uma história em desenvolvimento, obrigando-nos a interpretá-la sobretudo como um conjunto de processos de diferente índole (normativos, institucionais, sociais, políticos...) que potenciam oportunidades de luta pela dignidade humana. (Estêvão, 2012, p. 7).

Embora entendidos como universais nas concepções largamente difundidas, sobretudo desde a Declaração Universal dos Direitos Humanos, em 1948, "é sabido que os direitos humanos não são universais na sua aplicação" (Santos, 2010, p. 442). No entanto, ressalta o autor que "(...) as vicissitudes da aplicação não predeterminam a questão da validade dos direitos humanos" e apresenta, em síntese, pressupostos universalizantes presentes nas propostas de direitos humanos, as quais, justamente por essa pretensão, invalidam o caráter universal que apregoam.

O conceito de direitos humanos assenta num bem conhecido conjunto de pressupostos, todos eles tipicamente ocidentais, designadamente: existe uma natureza humana universal que pode ser conhecida racionalmente; a natureza humana é essencialmente diferente e superior à restante realidade: o indivíduo possui uma dignidade absoluta e irredutível que tem que ser defendida da sociedade ou do Estado; a autonomia do indivíduo exige que a sociedade esteja organizada de forma não hierárquica, como soma de indivíduos livres (Panikkar, 1948, p. 30, cit. em Santos, 2010, pp. 443-444).

As concepções, políticas e práticas em direitos humanos são diversas, em virtude de aspectos e contextos culturais, históricos, geográficos, econômicos que os condicionam. Evidentemente, não podem ser considerados de modo hegemônico.

Além disso, embora a fundamentação dos direitos humanos (em bases como a dignidade humana, por exemplo) acentue a sua anterioridade lógica face aos direitos, não é possível, contudo, separar os direitos das condições em que se concretizam, nem imunizá-los face às adaptações locais, sem que tal posicionamento implique, porém, a defesa de qualquer relativismo axiológico (Estêvão, 2012, p. 7). 
A resolução MEC/CNE n. ${ }^{\circ}$ 1, de 30 de maio de 2012, que estabelece diretrizes nacionais para a educação em direitos humanos, assume os direitos humanos como "(...) um conjunto de direitos civis, políticos, sociais, econômicos, culturais e ambientais, sejam eles individuais, coletivos, transindividuais ou difusos, referem-se à necessidade de igualdade e de defesa da dignidade humana" (Brasil, 2012). Essa resolução referenda-se num conjunto histórico de documentos nacionais e internacionais que visam assegurar os direitos humanos, com ênfase na educação:

Declaração Universal dos Direitos Humanos de 1948; a Declaração das Nações Unidas sobre a Educação e Formação em Direitos Humanos (Resolução A/66/137/2011); a Constituição Federal de 1988; a Lei de Diretrizes e Bases da Educação Nacional (Lei n 9.394/1996); o Programa Mundial de Educação em Direitos Humanos (PMEDH 2005/2014), o Programa Nacional de Direitos Humanos (PNDH-3/Decreto $n^{\circ} 7.037 / 2009$ ); o Plano Nacional de Educação em Direitos Humanos (PNEDH/2006); (Brasil, 2012).

As pesquisas do observatório de violências nas escolas da PUCPR, desde 2004, captam, nas vozes dos diferentes sujeitos, indícios de violação de direitos ao assinalarem um forte anseio por um direito fundamental aparentemente inerente às relações humanas e, em especial, nas relações pedagógico-educativas: o respeito. Essa expectativa, manifestada concomitantemente por estudantes, educadores e pais, pode ser um indicativo da necessidade de um olhar mais atento para a dinâmica dos sujeitos na/da escola e sociedade. Assim, nos recentes estudos do Observatório, assumimos como proposição para a superação das violências nas escolas: a proteção e a garantia de direitos.

Nesse texto, com o olhar a partir da escola, discutimos o trabalho em rede para a garantia de direitos e superação das violências nas escolas. Os dados aqui analisados são recortados da pesquisa: Educação básica de qualidade social para todos: políticas e práticas no contexto das escolas públicas. Realizado no período de 2010 a 2012, o estudo teve como objetivo o diagnóstico sobre questões relativas aos direitos humanos e às violências nas escolas e suas implicações na qualidade social da educação. A investigação abrangeu 14 escolas públicas de sete cidades do estado do Paraná (Araucária, Almirante Tamandaré, Campo Largo, Colombo, Curitiba, Pinhais e São José dos Pinhais), sendo sete escolas das respectivas redes municipais de ensino e sete escolas da rede estadual de ensino. As escolas 
estão localizadas em bairros populosos, pobres, com precária infraestrutura da periferia das cidades, caracterizados como de grande vulnerabilidade social. Na coleta de dados, foram ouvidos, mediante entrevistas estruturadas, 489 estudantes (crianças e adolescentes), 51 professores, 24 gestores (diretores e pedagogos), 47 funcionários técnico-administrativos das escolas, 148 pais e 14 conselheiros tutelares.

A apresentação e a discussão dos dados empíricos estão organizadas em tópicos. No primeiro são abordadas as tensões entre violências e garantia de direitos nas escolas, e no segundo a rede de proteção na garantia de direitos, considerando a importância da escola na rede e da rede na escola.

\section{Tensões entre violências e garantia de direitos nas escolas}

As diversas manifestações das violências nas escolas não se constituem fato ou fenômeno novo. Na história da educação são relatadas diferentes formas de violências, inclusive as perpetradas pela escola, por intermédio dos castigos e punições.

O castigo enquanto medida para formação do caráter é praticado em todas as sociedades humanas. Historicamente o homem tem interpretado a privação, a dor e o sofrimento como uma forma de aperfeiçoamento físico e moral da pessoa a quem é atribuída uma falta que precisa ser educada (Miguel \& Corrêa, 2011, p. 121)

No contexto contemporâneo, as inúmeras formas assumidas pelas manifestações de violências nas escolas são de amplo conhecimento público, sendo, inclusive, possível registrar as novas formas por elas adquiridas. Essas mudanças na configuração das violências, na diversificação e/ou ampliação das formas como têm se manifestado são mencionadas em Charlot (2002) quando aponta quatro novas faces que as violências nas escolas assumem.

Primeiramente surgiram formas de violência muito mais graves que outrora: homicídios, estupros, agressões com armas. É certo que são fatos que continuam muito raros, mas dão a impressão de que não há mais limite algum, que, daqui por diante, tudo pode acontecer na escola. (...) Em segundo lugar, os jovens envolvidos nos fatos de violência são cada vez mais jovens. (...) Em terceiro lugar, assiste-se, há alguns anos, a um aumento do número de intrusões externas na escola. (...) Em quarto lugar, os docentes e o pessoal administrativo da escola, nos bairros problemáticos, são, às vezes, objeto de atos repetidos, mínimos, que não são violências em si mesmos, mas cuja 
acumulação produz um estado de sobressalto, de ameaça permanente (...) (pp. 432-433).

Tais mudanças são indicativas da insegurança que adentra as escolas e produzem tensões e angústia social. A primeira face produz "uma angústia social face à violência na escola"; a segunda face provoca revisão da "representação de infância como inocência"; a terceira e quarta faces tornam a angústia social ainda mais aguda, diante da percepção de que a escola não se constitui mais um lugar seguro, conforme analisa Charlot (2002).

Diante desse quadro, profissionais da educação, pesquisadores e formuladores de políticas públicas têm analisado o fenômeno, buscando compreender suas causas e seus efeitos sobre alunos, pais, professores, gestores e outros protagonistas que constituem a comunidade escolar.

A preocupação com as crianças, os adolescentes e jovens passou a ser das famílias e das escolas, da sociedade, dos governos e da mídia, das ciências humanas, do direito e das políticas sociais. As condutas dos educandos nos obrigam a tentar saídas e intervenções coletivas. Por que essas formas de ser são tão surpreendentes em crianças e adolescentes? De onde elas vêm? Da escola? Das condições sociais e morais em que são socializadas fora das escolas? Poderiam ter sido evitadas? Temos poder de evitá-las? Ao menos dispomos de condições materiais e de artes para tratá-las? (Arroyo, 2007, p. 21).

As indagações interpelam-nos sobre as imagens das infâncias, adolescências e escolas com as quais operamos, provocando a busca de respostas que indiquem saídas. $\mathrm{Na}$ análise do fenômeno das violências nas escolas, convêm assinalar a afirmação de que "as crianças e adolescentes em seus rostos violentos ou em seus gestos indisciplinados, mais do que revelar-se, revelam o lado destrutivo da civilização" (Arroyo, 2007, p. 12) e lembrar-se da assertiva feita em Charlot (2002): "É preciso, inicialmente, distinguir a violência na escola, a violência à escola e a violência da escola" (p. 434).

A violência na escola é aquela que se produz dentro do espaço escolar, sem estar ligada à natureza e às atividades da instituição escolar: quando um bando entra na escola para acertar contas das disputas que são as do bairro, a escola é apenas o lugar de uma violência que teria podido acontecer em qualquer outro local. Pode-se, contudo, perguntar-se por que a escola, hoje, não está mais ao abrigo de violências que outrora se detinham nas portas da escola. 
A violência à escola está ligada à natureza e às atividades da instituição escolar: quando os alunos provocam incêndios, batem nos professores ou os insultam, eles se entregam a violências que visam diretamente a instituição e aqueles que a representam. Essa violência contra a escola deve ser analisada junto com a violência da escola: uma violência institucional, simbólica, que os próprios jovens suportam através da maneira como a instituição e seus agentes os tratam (modos de composição das classes, de atribuição de notas, de orientação, palavras desdenhosas dos adultos, atos considerados pelos alunos como injustos ou racistas...) (Charlot, 2002, pp. 434-435 - grifos nossos).

O autor conclui assegurando a necessidade de distinção acerca das diferentes origens, modos e protagonistas das violências, pois "se a escola é largamente (mas não totalmente) impotente face à violência na escola, ela dispõe (ainda) de margens de ação face à violência à escola e da escola" (Charlot, 2002, p. 435). Grande parte das manifestações de violências nas escolas pode ser configurada como violação de direitos.

A escola e o educador exercem, inevitavelmente, uma influência constante e ativa na vida de crianças e adolescentes, portanto é importante que tenham conhecimentos sobre as violências para intervir quando detectar alguma situação de violências com seus alunos (Brasil, 2007).

Assim, torna-se fundamental a permanente atenção sobre a existência das violências nas escolas, via diagnósticos que permitam a compreensão das especificidades das dinâmicas dos sujeitos em cada contexto e, a partir daí, a definição de estratégias de intervenção. O reconhecimento da existência e das suas possíveis configurações poderá deflagrar possíveis ações. Entretanto, o desconhecimento, a invisibilidade ou negação geram a inação, o que poderá agravar a violação de direitos no espaço escolar.

O estudo empírico, no qual ouvimos estudantes, professores, gestores, funcionários e pais, apresenta percepções bastante elucidativas para a compreensão do fenômeno nas escolas. De modo geral, os sujeitos que estão mais presentes e atuantes no cotidiano escolar afirmam que existem violências, embora as considerem poucas. Talvez, em virtude da frequência, as manifestações de violências passem aparência de normalidade, podendo adquirir invisibilidade aos olhos de muitos.

Os pais, por sua vez, afirmam, em maior número, que não existe violência nas escolas e tal percepção pode ser em virtude da falta de proximidade que os pais têm da dinâmica do cotidiano escolar. A convivência que pais e familiares têm com a escola não ultrapassa, em muitos casos, os 
portões, nos quais entregam e buscam seus filhos e nas raras reuniões, normalmente informativas, para as quais são convocados. Negar que existam violências nas escolas também pode ser um mecanismo para atenuar a angústia social referida por Charlot (2002).

\section{Tabela 1 - Percepção sobre as violências nas escolas}

\begin{tabular}{lrrrrr}
\hline GRAU DE VIOLÊNCIA & Alunos & Prof. & Gestores & Func. & Pais \\
\hline Há Violência & $24,7 \%$ & $37,3 \%$ & $50,0 \%$ & $21,3 \%$ & $19,6 \%$ \\
Pouca Violência & $47,7 \%$ & $47,1 \%$ & $45,0 \%$ & $38,3 \%$ & $41,9 \%$ \\
Há Violência sem Controle & $13,9 \%$ & $3,9 \%$ & - & $4,3 \%$ & $2,0 \%$ \\
Extrema Violência & $6,3 \%$ & $3,9 \%$ & - & - & $2,0 \%$ \\
Não existe Violência & $7,0 \%$ & $5,9 \%$ & $5,0 \%$ & $19,2 \%$ & $\mathbf{2 8 , 4} \%$ \\
Não resposta & $0,4 \%$ & $2,0 \%$ & - & $17,0 \%$ & $6,1 \%$ \\
Total & $100 \%$ & $100 \%$ & $100 \%$ & $100 \%$ & $100 \%$ \\
\hline
\end{tabular}

Fonte: Dados da pesquisa "Educação básica de qualidade para todos: políticas e práticas no contexto das escolas públicas", realizada pela equipe do Observatório de Violências nas Escolas PUCPR.

Diante da pergunta: "O que entende por violências?", os participantes tiveram dificuldade em explicar o significado, passando a identificar os tipos de manifestações que presenciam nas escolas, citando a violência física como a mais frequente, seguida da violência verbal. Esses posicionamentos mantiveram-se, ao serem interrogados, mediante questão fechada, sobre quais os tipos de violência mais comuns observados na escola.

Os estudos confirmam que as violências evidenciam-se por intermédio de agressões e constrangimentos que podem ser: físicos - empurrões, cutucões, socos, pontapés, esbarrões; verbais - apelidos, deboches, ameaças; sociais - exclusão, isolamento, descaso; simbólicos desigualdades, preconceitos, discriminação, relações de poder, currículos hegemônicos, monoculturais e etnocêntricos. O vandalismo, ou seja, a violência contra o patrimônio e equipamentos públicos, é outro tipo de violência bastante presente no cotidiano escolar, que "embora não sejam dirigidas diretamente contra as pessoas, afetam os sujeitos na esfera individual e social" (Eyng, 2009, p. 89). 
As percepções dos participantes do estudo empírico indicam as agressões físicas e verbais como sendo as principais formas de manifestações das violências nas escolas, confirmando estudos e resultados de pesquisas de diferentes autores. Infelizmente, as violências estão bem visíveis nos espaços escolares. Certamente não é possível ignorá-las, pois direitos violados fazem com que a escola deixe de cumprir sua finalidade educativa, como espaço de garantia e vivência de direitos.

A escola, sob esse aspecto, é concebida como o espaço onde crianças e adolescentes têm o direito de desenvolver plenamente todas as suas potencialidades (física, intelectual, social, estética, ética, entre outras) e de exercer sua cidadania de forma integral, sentindo-se parte de um coletivo que os apoia nas diferentes etapas de desenvolvimento (Brasil, 2007, p. 41).

O pleno desenvolvimento depende da efetivação da educação básica como direito universal e alicerce para o exercício da cidadania e conquista dos demais direitos, conforme define a resolução CNE/CEB n. ${ }^{\circ} 4$ de 13 de julho de 2010, no artigo $5^{\circ}$.

A educação Básica é direito universal e alicerce indispensável para o exercício da cidadania em plenitude, da qual depende a possibilidade de conquistar todos os demais direitos, definidos na Constituição Federal, no Estatuto da Criança e do Adolescente (ECA), na legislação ordinária e nas demais disposições que consagram as prerrogativas do cidadão (Brasil, 2010a).

Entretanto, considerando as condições presentes no contexto escolar, os direitos de acesso e permanência numa escola entendida como espaço de exercício de direitos e de pleno desenvolvimento se efetiva? Ou perguntando de outro modo: os direitos de crianças e adolescentes estão sendo garantidos no espaço escolar?

Nessa direção, perguntamos aos participantes da pesquisa sobre quais as suas expectativas de direitos. O direito mais almejado, segundo posicionamentos dos estudantes, embora suas expectativas estejam distribuídas pelos diferentes direitos previstos na legislação, apontam o respeito como o mais importante, sendo esse também o direito mais indicado pelos professores. 
Tabela 2 - Expectativa de direitos, segundo os participantes

\begin{tabular}{|c|c|c|c|c|c|c|}
\hline & Alunos & Professores & Gestores & Funcionários & Conselho & Pais \\
\hline Alimentação & $3,8 \%$ & - & - & $1,9 \%$ & - & $0,7 \%$ \\
\hline $\begin{array}{l}\text { Convivência familiar e } \\
\text { comunitária }\end{array}$ & $12,1 \%$ & $9,8 \%$ & $8,3 \%$ & $24,1 \%$ & $20,0 \%$ & $13,5 \%$ \\
\hline Cultura & $2,5 \%$ & $3,9 \%$ & - & - & - & $0,7 \%$ \\
\hline Dignidade & $3,1 \%$ & $9,8 \%$ & $12,5 \%$ & $13,0 \%$ & $6,7 \%$ & $9,5 \%$ \\
\hline Educação & $10,6 \%$ & $3,9 \%$ & $20,8 \%$ & $3,7 \%$ & - & $23,0 \%$ \\
\hline Esporte & $2,0 \%$ & - & _- & $1,9 \%$ & _- & _- \\
\hline Lazer & $1,8 \%$ & _- & _- & _- & _- & $1,4 \%$ \\
\hline Liberdade & $6,1 \%$ & $11,8 \%$ & - & $7,4 \%$ & - & $6,8 \%$ \\
\hline Profissionalização & $1,6 \%$ & $2,0 \%$ & - & - & - & $2,0 \%$ \\
\hline Respeito & $25,2 \%$ & $25,5 \%$ & $20,8 \%$ & $24,1 \%$ & - & $21,0 \%$ \\
\hline Saúde & $18,7 \%$ & $7,8 \%$ & $12,5 \%$ & $9,3 \%$ & $6,7 \%$ & $18,9 \%$ \\
\hline Vida & $11,7 \%$ & $23,5 \%$ & $25,0 \%$ & $13,0 \%$ & $60,0 \%$ & $1,4 \%$ \\
\hline Não resposta & $0,7 \%$ & $2,0 \%$ & _- & $1,9 \%$ & $6,7 \%$ & $1,4 \%$ \\
\hline
\end{tabular}

Fonte: Dados da pesquisa "Educação básica de qualidade para todos: políticas e práticas no contexto das escolas públicas", realizada pela equipe do Observatório de Violências nas Escolas PUCPR.

A maior expectativa de direito de estudantes e professores é nominalmente a mesma, contudo o que ambos os grupos esperam como evidência desse direito é diametralmente oposto. Enquanto os estudantes indicam que entendem o respeito como direito a ter voz, poderem falar e serem ouvidos pelos seus educadores, por sua vez, os professores entendem que estarão usufruindo do respeito quando os seus educandos se mantiverem quietos, ficarem em silêncio. Sem dúvida, falta diálogo; entretanto, vale assinalar que a garantia de direitos de estudantes é viabilizada concomitantemente com a garantia de direitos dos professores.

O diálogo entre educadores e educandos precisa ser mediado pela compreensão dos direitos, deveres e responsabilidades estabelecidos na escola e na sociedade. É importante entender o respeito como direito, conforme estabelece o Estatuto da Criança e do Adolescente (ECA), no artigo $15^{\circ}$ : "A criança e o adolescente têm direito à liberdade, ao respeito e à dignidade como pessoas humanas em processo de desenvolvimento e como sujeitos de direitos civis, humanos e sociais garantidos na Constituição e nas leis" (Brasil, 1990). No artigo 17², do mesmo estatuto, está especificado no 
que consiste o direito ao respeito. "O direito ao respeito consiste na inviolabilidade da integridade física, psíquica e moral da criança e do adolescente, abrangendo a preservação da imagem, da identidade, da autonomia, dos valores, ideias e crenças, dos espaços e objetos pessoais" (Brasil, 1990).

O direito à educação, previsto no artigo 53 do estatuto, também contempla o direito de o estudante ser respeitado por seus educadores, indicando inclusive o direito de posicionar-se.

A criança e o adolescente têm direito à educação, visando ao pleno desenvolvimento de sua pessoa, preparo para o exercício da cidadania e qualificação para o trabalho, assegurando-se-lhes:

I - igualdade de condições para o acesso e permanência na escola;

II - direito de ser respeitado por seus educadores;

III - direito de contestar critérios avaliativos, podendo recorrer às instâncias escolares superiores;

IV - direito de organização e participação em entidades estudantis;

V - acesso à escola pública e gratuita próxima de sua residência (Brasil, 1990 - grifos nossos).

Nesse contexto, compreender a escola como espaço estratégico na efetivação da rede de proteção e garantia de direitos implica no desenvolvimento de ações para superação de toda sorte de manifestações de violências que podem afetar crianças e adolescentes, quer ocorram dentro ou fora da escola.

\section{A rede de proteção na garantia de direitos: a escola na rede e a rede na escola}

O trabalho em rede tem o potencial de fortalecer sujeitos e ações na perspectiva da garantia de direitos. Amaral (2010, p. 1) explica os significados de rede, distinguindo o sentido morfológico do sentido de articulação, conexão de pessoas. Assim, "do ponto de vista morfológico, estrutural, imagine uma rede de pescar, com linhas se entrecruzando, formando um nó, um ponto de encontro, e formando outro nó, outro ponto de conexão e assim por diante". E do ponto de vista do modo de articulação de pessoas que se organizam com vistas à conexão de esforços em rede num projeto comum, "estamos dizendo que as relações internas do seu sistema de relações, dos elementos que as 
formam, se dão como numa rede, a partir de conexões, ponto a ponto, entre as pessoas e instituições" (Amaral, 2010, p. 1).

A estratégia em rede com vistas à proteção de direitos está prevista no artigo $86^{\circ}$ do ECA, que estabelece: "A política de atendimento dos direitos da criança e do adolescente far-se-á através de um conjunto articulado de ações governamentais e não governamentais, da União, dos Estados, do Distrito Federal e dos Municípios" (Brasil, 1990).

O trabalho da escola, integrando as redes de proteção, é um jeito de contribuir para o fortalecimento das ações de garantia e proteção de direitos de crianças e adolescentes. Sobretudo, considerando que "o papel da escola é superar as práticas isoladas, pois é a única instituição que trabalha com grande parte da população em seus espaços e tempos" (Brasil, 2007).

Em relação às crianças e aos adolescentes, essa responsabilidade é ainda maior, diante da quase universalização do acesso dessa população no espaço escolar. Os índices divulgados pelo Instituto de Geografia e Estatística (IBGE) indicam que "na faixa etária de 6 a 14 anos, desde meados da década de 1990, praticamente todas as crianças brasileiras já estavam frequentando a escola" (Brasil, 2010b, p. 46). Nessa faixa etária, $94,2 \%$ da população frequentava a escola em 1999, índice que subiu para 96,1\% em 2004 e para $97,6 \%$ em 2010, segundo o Instituto. Fica evidente a importância estratégica da escola, na rede de proteção e garantia de direitos de crianças e adolescentes.

Ao se integrar à Rede de Proteção, a escola torna-se um canal estratégico para a efetividade das ações de garantia dos direitos das crianças e adolescentes, oferecendo informações, conhecimentos, experiências e capacitação aos operadores da Rede e a educadores e demais profissionais envolvidos com o universo escolar e com o dia a dia de crianças e adolescentes (Brasil, 2007, p. 41).

A rede de proteção que integre ações governamentais e não governamentais precisa reunir um conjunto de especialidades advindas de diferentes órgãos, cujos esforços sejam demandados como necessários na resolução das situações que violem direitos ou exponham crianças e adolescentes ao risco para a violência.

A proteção de diretos de crianças e adolescentes, no Brasil a partir de 1990 com o ECA, tem um significativo avanço na criação do Conselho Tutelar, aplicando os princípios da descentralização político-administrativa e da 
participação da população, estabelecidos nos incisos I e II do artigo 204 da Constituição Federal.

I - descentralização político-administrativa, cabendo a coordenação e as normas gerais à esfera federal e a coordenação e a execução dos respectivos programas às esferas estadual e municipal, bem como a entidades beneficentes e de assistência social;

II - participação da população, por meio de organizações representativas, na formulação das políticas e no controle das ações em todos os níveis (Brasil, 1988).

O Conselho Tutelar atende a esses dois princípios. Na sua definição, estabelecida no artigo 131 do ECA, como: "órgão permanente e autônomo, não jurisdicional, encarregado pela sociedade de zelar pelo cumprimento dos direitos da criança e do adolescente, definidos nesta Lei" (Brasil, 1990) e também na sua jurisdição e composição, segundo o artigo 132: "Em cada município haverá, no mínimo, um Conselho Tutelar composto de cinco membros, eleitos pelos cidadãos locais para mandato de três anos, permitida uma reeleição" (Brasil, 1990).

As atribuições do Conselho Tutelar, estabelecidas no mesmo estatuto, em seu artigo 136, indicam a importância e abrangência das ações desse órgão na proteção de direitos, tanto no atendimento direto de crianças e adolescentes, quanto aos seus pais e familiares.

$\mathrm{I}$ - atender as crianças e adolescentes nas hipóteses previstas nos arts. $98 \mathrm{e}$ 105 , aplicando as medidas previstas no art. 101, I a VII;

II - atender e aconselhar os pais ou responsável, aplicando as medidas previstas no art. 129, I a VII;

III - promover a execução de suas decisões, podendo para tanto:

a) requisitar serviços públicos nas áreas de saúde, educação, serviço social, previdência, trabalho e segurança;

b) representar junto à autoridade judiciária nos casos de descumprimento injustificado de suas deliberações.

IV - encaminhar ao Ministério Público notícia de fato que constitua infração administrativa ou penal contra os direitos da criança ou adolescente;

V - encaminhar à autoridade judiciária os casos de sua competência;

VI - providenciar a medida estabelecida pela autoridade judiciária, dentre as previstas no art. 101, de I a VI, para o adolescente autor de ato infracional;

VII - expedir notificações; 
VIII - requisitar certidões de nascimento e de óbito de criança ou adolescente quando necessário;

IX - assessorar o Poder Executivo local na elaboração da proposta orçamentária para planos e programas de atendimento dos direitos da criança e do adolescente;

$X$ - representar, em nome da pessoa e da família, contra a violação dos direitos previstos no art. $220, \S 3^{\circ}$, inciso II, da Constituição Federal;

XI - representar ao Ministério Público, para efeito das ações de perda ou suspensão do pátrio poder (Brasil, 1990).

No contexto atual, indiscutivelmente, o Conselho Tutelar assume papel vital na proteção de direitos de crianças e adolescentes. Mas e quanto à escola? Qual papel tem assumido? Na perspectiva da integração da escola na rede de proteção, perguntamos aos pais, professores, funcionários, gestores e conselheiros tutelares: quais são os parceiros da escola no trabalho em rede para a proteção de direitos de crianças e adolescentes?

Tabela 3 - Parceiros da escola no trabalho em rede

\begin{tabular}{lccccc}
\hline & Pais & Professores & Funcionários & Gestores & $\begin{array}{c}\text { Conselheiros } \\
\text { Tutelares }\end{array}$ \\
\hline $\begin{array}{l}\text { Polícia e agentes } \\
\text { de segurança }\end{array}$ & $18,6 \%$ & $29,0 \%$ & $23,3 \%$ & $10,5 \%$ & $15,4 \%$ \\
$\begin{array}{l}\text { Comunidade e } \\
\text { empresas }\end{array}$ & $2,5 \%$ & $14,5 \%$ & $13,3 \%$ & $13,2 \%$ & - \\
$\begin{array}{l}\text { Orgãos públicos } \\
\text { governamentais }\end{array}$ & $1,7 \%$ & $14,5 \%$ & $15,0 \%$ & $42,1 \%$ & $77,0 \%$ \\
$\begin{array}{l}\text { Conselho tutelar } \\
\text { Família }\end{array}$ & $9,3 \%$ & $12,9 \%$ & $18,3 \%$ & $21,0 \%$ & - \\
$\begin{array}{l}\text { Profissionais da } \\
\text { educação }\end{array}$ & $1,7 \%$ & $1,6 \%$ & $1,7 \%$ & $2,6 \%$ & - \\
$\begin{array}{l}\text { Não sabe/Não } \\
\text { tem }\end{array}$ & $3,4 \%$ & - & $5,0 \%$ & $2,6 \%$ & - \\
Outros & $7,6 \%$ & $27,4 \%$ & $23,3 \%$ & $7,9 \%$ & $7,6 \%$ \\
$\begin{array}{l}\text { Total de } \\
\text { respostas }\end{array}$ & $99,99 \%$ & $99,9 \%$ & $99,9 \%$ & $99,9 \%$ & $100 \%$ \\
\hline \hline
\end{tabular}

Fonte: Dados da pesquisa "Educação básica de qualidade para todos: políticas práticas no contexto das escolas públicas", realizada pela equipe do Observatório de Violências nas Escolas PUCPR.

O desconhecimento, indicado nas respostas de pais, professores e funcionários ao dizerem que não sabem ou que não têm parcerias, é sintoma 
da fragilidade ou inexistência do trabalho em rede nas escolas. Essa constatação também se evidencia nas poucas indicações de que os profissionais da educação se constituem parceiros no trabalho em rede.

A integração da escola às Redes de Proteção é também uma forma de contribuir para o fortalecimento e para a ampliação das ações de enfrentamento à violência contra crianças e adolescentes, a partir do envolvimento das comunidades em torno dessa questão (Brasil, 2007, p. 40).

Crianças e adolescentes convivem na escola e na família, logo, escola e família precisam se integrar ou serem integrados na rede de proteção e garantia de direitos. Do mesmo modo que a escola, a família também ainda não é percebida como parceira no trabalho em rede. É preocupante o entendimento do papel da família, entre os profissionais da educação e de conselheiros tutelares, pois parece que a visão de família está ainda mais vinculada à ideia de espaço de violação do que de proteção e garantia de direitos. Assim, poucos consideram a família como parceira, integrando o trabalho em rede.

Também é problemática a alta incidência na indicação da polícia e outros agentes de segurança como parceiros principais no trabalho em rede. Está muito presente a ideia de "vigiar e punir" (Foucault, 2002).

A garantia, proteção e vivência de direitos, em contextos caracterizados pela desigualdade e pela exclusão, é tarefa complexa e coletiva. Os esforços necessários são, portanto, requeridos de toda a sociedade. Nesse caso, concordamos com Rizzini (2002) que sozinhos não chegamos muito longe. "Por isso, a integração de ideias, esforços é fundamental para enfrentarmos os desafios da luta por um mundo mais justo e igualitário" (p. 16).

O grande benefício do trabalho em rede está na ampliação de forças e competências que mobilizam conhecimentos e experiências imbricados numa práxis interdisciplinar. A junção de forças supera, assim, tanto os sentimentos de impotência, diante de tão grandes injustiças e desafios, quanto os sentimentos de onipotência.

$\mathrm{Na}$ intervenção em redes, o profissional não se vê nem impotente nem onipotente, mas como um sujeito inserido nas relações sociais para fortalecer, a partir das questões históricas do sujeito e das suas relações particulares, as relações destes mesmos sujeitos para ampliação de seu poder, saber, e de seus capitais (Faleiros, 1999, p. 25). 
A intervenção em rede requer, dos participantes, a compreensão das limitações de ações solitárias e das potencialidades de ações cujas intencionalidades sejam compartilhadas por um maior número de sujeitos articulados e mobilizados numa práxis interdisciplinar. O desenvolvimento de propósitos e estratégias interdisciplinares pode ser mais bem viabilizado se os participantes adotarem atitude de humildade, compreendendo suas possibilidades e próprias limitações. Só assim poderá haver a parceria, assentada na comunicação, abertura e reciprocidade para e com os conhecimentos, habilidades e experiências do outro, na resolução das demandas do trabalho em rede.

Com a finalidade de conhecer os posicionamentos dos participantes sobre a intervenção em rede, perguntamos a eles: "Quais os benefícios do trabalho em rede?". Os resultados advindos das respostas a essa questão, embora dispersas, confirmam o que os estudos e políticas indicam como finalidades e benefícios do trabalho em rede. As indicações, comuns nas falas dos diferentes grupos de participantes da pesquisa, ainda que com ênfases diferentes, quanto aos benefícios da intervenção em rede são: 1. Melhora da qualidade educacional; 2. Ação conjunta, parcerias.

Outra manifestação, presente em falas de todos os grupos de sujeitos da amostra investigada, são indicações de "não sabe" e "não tem". Tanto o desconhecimento como a indicação de não haver benefícios confirmam a fragilidade, inexistência e/ou pouca participação dos sujeitos pesquisados nas intervenções em rede.

Embora a proposta de intervenção em rede não seja recente, sua necessidade e potencialidades têm sido reafirmadas no contexto contemporâneo; entretanto, os processos formativos para atuação integrada e interdisciplinar ainda são incipientes. A formação inicial e continuada para o trabalho em rede, incluindo a família e as comunidades, além de órgãos governamentais e organizações não governamentais, poderá criar condições diante dos desafios que lhe são demandados.

Para que essa integração aconteça é preciso que os gestores, professores e demais profissionais que atuam na educação estejam preparados para o reconhecimento, a prevenção e o enfrentamento das diferentes situações de violência a que está exposta a população infantojuvenil. É fundamental que as famílias e as comunidades sejam incluídas nesse debate, a fim de que elas participem do processo, tanto na condição de sujeitos passíveis de proteção 
quanto na de parceiros na garantia e promoção dos direitos dessa população (Brasil, 2007, p. 40).

Tabela 4 - Benefícios do trabalho em rede

\begin{tabular}{lccccc}
\hline & Pais & Professores & Funcionários & Gestores & Cons Tut. \\
\hline Comunicação/diálogo & 2,3 & 16,2 & - & 4,5 & 7,1 \\
Ação conjunta/parcerias & 13,6 & 9,3 & 9,5 & 22,8 & 7,1 \\
Agilidade & 5,7 & - & - & 4,5 & 57,1 \\
Qualidade educacional & 33,0 & 25,6 & 50,0 & 13,7 & 7,1 \\
Ação de especialistas & - & & - & 9,1 & 7,1 \\
Garantia de direitos & - & 7,0 & 9,5 & 9,1 & 7,1 \\
Participação da família & - & & 7,1 & - & - \\
Aumenta resultados & - & 7,0 & 4,9 & 18,2 & - \\
Aumenta segurança & 8,0 & & - & - & - \\
Fortalecimento dos suj. & - & 9,3 & - & 13,6 & - \\
Não sabe/Não tem & 28,4 & 14,0 & 19,0 & 4,5 & 7,1 \\
Outros & 9,0 & 11,6 & - & - & - \\
Total de respostas & 100 & 100 & 100 & 100 & 99,7 \\
\hline
\end{tabular}

Fonte: Dados da pesquisa "Educação básica de qualidade para todos: políticas e práticas no contexto das escolas públicas", realizada pela equipe do Observatório de Violências nas Escolas PUCPR.

O preparado para o reconhecimento, a prevenção e o enfrentamento das diferentes situações de violência a que está exposta a população infantojuvenil exige formação inicial e continuada de professores, gestores e demais profissionais que atuam na educação. Além desses, os pais, responsáveis e diferentes membros da comunidade que atuem ou venham a colaborar na rede de proteção de direitos também necessitam de uma formação básica.

Os participantes da pesquisa empírica foram indagados sobre: "Quais os desafios a serem vencidos para o trabalho em rede?". Nas respostas, os participantes confirmam a necessidade de criar as condições que caracterizam uma rede de proteção e os benefícios, potencialidades desse trabalho. 
Tabela 5 - Desafios para o trabalho em rede

\begin{tabular}{lccccc}
\hline & Pais & Professores & Funcionários & Gestores & Cons. Tutelares \\
\hline Melhorar a educação & 7,5 & 6,3 & 9,1 & 4,0 & - \\
Integr./comunicação, & 13,2 & 10,4 & 6,8 & 12,0 & 23,1 \\
diálogo & & & & & \\
Envolv. da & 10,4 & 4,2 & 9,1 & - & - \\
comunidade & 7,5 & 8,3 & 6,8 & - & - \\
Condições da escola & 8,5 & 2,1 & - & 4,0 & - \\
Ações Preventivas & 4,7 & 12,5 & 13,6 & 16,0 & - \\
Participação dos pais/ & 3,8 & 4,2 & 4,5 & 4,0 & 7,7 \\
família & 10,4 & - & - & 4,0 & - \\
Combate às drogas & - & 35,4 & 2,3 & 16,0 & 46,1 \\
Melhora seg/polic. & - & 2,1 & 2,3 & 12,0 & 7,7 \\
Fortalecimento da rede & - & 4,2 & - & 8,0 & 7,7 \\
Formação & - & - & - & - & 7,7 \\
Agilizar/desburocratizar & - & - & 18,2 & & - \\
Aceitar limitações & - & - & - & 8,0 & - \\
Ações dos órgãos gov. & - & - & - & 4,0 & - \\
Superar as violências & 30,2 & 4,1 & 22,8 & - & - \\
Garantia de direitos & 3,8 & 6,2 & 4,5 & 8,0 & \\
Não sabe/Não tem & & & & & \\
Outros & & & &
\end{tabular}

Fonte: Dados da pesquisa "Educação básica de qualidade para todos: políticas e práticas no contexto das escolas públicas", realizada pela equipe do Observatório de Violências nas Escolas PUCPR.

Os desafios apresentados pelos participantes podem ser agrupados em dois aspectos: 1) Desafios para que o trabalho da rede se efetive considerando a necessidade de serem criadas as condições de infraestrutura de pessoas, materiais e estratégias para ação; 2) Desafios demandados do trabalho em rede - considerando os resultados esperados a partir dos encaminhamentos de solução realizados pela ação em rede.

No primeiro grupo destacam-se: Fortalecimento da rede; Integração, comunicação, diálogo; Formação; Condições da escola; Envolvimento da comunidade; Participação dos pais, família; Agilizar, desburocratizar; Aceitar limitações; Ações dos órgãos governamentais. O conjunto de aspectos é realmente desafiador e ao mesmo tempo condicionante para a efetivação do trabalho em rede. As respostas a esse questionamento reafirmam as indicações anteriores quanto à necessidade do fortalecimento dos atores e da própria rede, viabilizando a comunicação e a integração para que a ação conjunta tenha êxito. 
No segundo grupo, temos: Melhorar a educação; Combate às drogas; Superar as violências; Garantia de direitos; Ações Preventivas; Melhora segurança/policiamento. Tais desafios requerem formação, fator indispensável para a garantia de direitos. Nesse sentido, a "Educação em Direitos Humanos, com a finalidade de promover a educação para a mudança e a transformação social" (Brasil, 2012) poderá orientar as estratégias de formação necessárias e, assim, almejarmos a "Educação em Direitos Humanos como processo sistemático e multidimensional, orientador da formação integral dos sujeitos de direitos" (Brasil, 2012).

O propósito da rede de proteção é a garantia de direitos de crianças e adolescentes. $O$ fato de que a maior parte das respostas esteja indicando as condições para a configuração e desenvolvimento do trabalho em rede, em vez de ações protetivas, evidencia como necessidades e desafios prioritários a formação dos sujeitos, a alocação de recursos e a criação permanente de estratégias que tenham efetividade política e relevância cultural.

\section{Desafios na tessitura da rede de proteção}

A tessitura de uma rede de proteção para a garantia de direitos de crianças e adolescentes é processo, é dinâmica, tal como a própria essência da rede, que se caracteriza pelo movimento, pela dinâmica na atuação interdisciplinar. $O$ seu movimento requer diálogo com, na e entre a diversidade, que constitui e circula no espaço escolar. Esse diálogo, na perspectiva intercultural que valorize a dignidade de todas as pessoas, implica considerar a visão intercultural de direito numa abordagem hermenêutica diatópica, conforme nos ensina Santos (2010).

A partir do diagnóstico, apresentado nesse estudo, podem ser esboçadas ações estratégicas no fortalecimento dos sujeitos para as múltiplas configurações que $\mathrm{o}$ trabalho de proteção e garantia de direitos venha demandar. Essas ações abrangem políticas e programas governamentais e da sociedade civil. Entretanto, esboçaremos aqui possibilidades e necessidades, ou seja, desafios, com foco na escola. Isso em virtude da necessidade de criar condições para que a escola seja entendida e atuante como espaço estratégico na proteção e garantia de direitos. Para a superação dos desafios, sugerimos: 
1. Programas de convivência na superação das violências nas escolas, sob forma de agressões físicas, verbais, discriminações, exclusão, entre outros, que violam direitos;

2. A vivência e garantia de direitos na convivência escolar, sobretudo o respeito;

3. Adoção de concepções pós-críticas no currículo escolar, em função do potencial que essas perspectivas apresentam para promover o diálogo com e na diversidade;

4. Inserção da educação em direitos humanos nos projetos pedagógicos dos cursos de formação de professores para a educação básica;

5. Inserção interdisciplinar da educação em direitos humanos nos projetos pedagógicos e nos planos de ensino de toda a educação básica;

6. Emancipação dos sujeitos, com suporte na vivência em processos participativos, que deem voz às crianças, aos adolescentes, aos jovens e aos adultos envolvidos nos processos.

Em síntese, na tessitura da rede de proteção de direitos, faz-se necessário compreender a origem e a dinâmica das tensões que circulam e atravessam o contexto escolar; o jogo de forças, interesses e a diversidade ali existente e, assim, converter a escola em espaço de garantia de direitos via diálogo com a diversidade cultural, incluindo a igualdade e a diferença de cultura, gênero, raça, etnia, orientação/identidade sexual.

\section{Referências}

Amaral, V. (2010). Conectando pessoas tecendo redes. Disponível em www.searh.rn.gov.br/contentproducao/aplicacao/searh_escola/arquivos/pdf/ paper-tecendoredes-vivianeamaral.pdf (acesso em 16 nov. 2010).

Arroyo, M. G. (2007). Imagens quebradas: Trajetórias e tempos de alunos e mestres (4a ed.). Petrópolis, RJ: Vozes.

Bobbio, N. (2004). A era dos direitos ( $3^{\mathrm{a}}$ reimp.). Rio de Janeiro: Elsevier.

Brasil (1988). Constituição Federal. Brasília. Disponível em http://www.planalto.gov.br/ccivil_03/Constituicao/Constituiçao.htm (acesso em 18 jun. 2009). 
Brasil (1990). Estatuto da Criança e do Adolescente. Disponível em http://www.planalto.gov.br/ccivil/LEIS/L8069.htm (acesso em 20 maio 2009).

Brasil (1996). Lei Federal n. ${ }^{\circ}$ 9.394/1996. Lei de Diretrizes e Bases da Educação Nacional - LDB. Brasília. Disponível em http://portal.mec.gov.br (acesso em 18 jun. 2009).

Brasil (2007). Comitê Nacional de Educação em Direitos Humanos. Plano Nacional de Educação em Direitos Humanos: 2007. Brasília: Secretaria Especial dos Direitos Humanos, MEC, MJ, UNESCO. Disponível em http://www.mj.gov.br/sedh/edh/pnedhpor.pdf (acesso em 18 jun. 2009).

Brasil (2007). Proteger para educar: A escola articulada com as redes de proteção de crianças e adolescentes (Cadernos Secad 5). Brasília: Secretaria de Educação Continuada, Alfabetização e Diversidade (Secad/MEC).

Brasil (2010a). Resolução CNE/CEB n. ${ }^{\circ}$, de 13 de julho de 2010. Diário Oficial da União, Brasília, 14 de julho de 2010, Seção 1, p. 824.

Brasil (2010b). Síntese de indicadores sociais: Uma análise das condições de vida da população brasileira. Rio de Janeiro: Instituto Brasileiro de Geografia e Estatística.

Brasil (2012). Resolução $n .^{\circ}$ 1, de 30 de maio de 2012. Diário Oficial da União, Brasília, n. ${ }^{\circ}$ 105, 31 de maio de 2012, Seção 1, página 48.

Charlot, B. (2002). A violência na escola: Como os sociólogos franceses abordam essa questão. Sociologias, 4(8), 432-443.

Estêvão, C. V. (2012). Direitos humanos, justiça e educação na era dos mercados. Porto: Porto Editora.

Eyng, A. M. (2009). O observatório de violências nas escolas PUCᄀPR: Pesquisa e intervenção. In R. T. Ens, M. A. Behrens \& D. S. R. Vosgerau (Org.), Trabalho do professor no espaço escolar (pp. 87-110). Curitiba: Champagnat.

Faleiros, V. P. (1999). Estratégias em Serviço Social (2a ed.). São Paulo: Cortez.

Foucault, M. (2002). Vigiar e punir: Nascimento da prisão (26 ed.). Petrópolis: Vozes.

Miguel, M. E., \& Correa, R. L. (2011). O castigo como violência na formação do caráter e na disciplinarização do corpo. In A. M. Eyng (Org.), Violências nas escolas: Perspectivas históricas e políticas. ljuí: Ed. Unijuí.

Rizzini, I. (2002). Solidariedade e comprometimento nas intenções e nas ações. In M. G. M. Türck, Rede interna e rede social: $O$ desafio permanente na teia das relações sociais. Porto Alegre: Tomo Editorial.

Santos, B. S. (2010). A gramática do tempo (3 ${ }^{\mathrm{a}}$ ed.). São Paulo: Cortez. 


\title{
HUMAN RIGHTS AND VIOLENCE IN SCHOOLS: CHALLENGES OF THE NETWORK
}

\begin{abstract}
The guarantee of rights constitutes itself as the main route for overcoming violence in schools. This proposition implies networking and requires joint efforts. Although the school constitutes a strategic space in the execution of the network, the actions enthralled from the school and in school are still fragile. This observation motivates the study reported here, which investigates the perceptions of school administrators, teachers, parents and council members on the safety net in ensuring the rights of children and adolescents. The presentation and discussion of the empirical data are analyzed addressing tensions between violence and rights guarantee in schools and safety net in establishing rights. Diagnostic results, presented in this study, allow sketching strategic actions to strengthen the subjects for the multiple settings that work to protect and guarantee the rights demand from school..
\end{abstract}

\section{Keywords}

Educational policies; Violence in Schools; Rights guarantee; Rights protection network

DERECHOS HUMANOS Y VIOLENCIA EN LAS ESCUELAS: DESAFIOS DEL TRABAJO EN RED

\footnotetext{
Resumen

La garantía de los derechos constituye la principal vía para la superación de la violencia en las escuelas. Esta propuesta implica la creación de redes y requiere esfuerzos conjuntos. Aunque la escuela sea un espacio estratégico en la ejecución de la red, las acciones cautivadas de la escuela y en la escuela siguen siendo frágiles. Esta observación motiva el estudio informado aquí, que investiga las percepciones de los administradores de la escuela, maestros, padres y miembros del consejo de la red de seguridad para
} 
266 Ana Maria Eyng

garantizar los derechos de los niños y adolescentes. La presentación y discusión de los datos empíricos son analizados frente a las tensiones entre la violencia y la garantía de los derechos en las escuelas y la red de seguridad en el establecimiento de derechos. Los resultados del diagnóstico se presentan en este estudio permiten esbozar acciones estratégicas para fortalecer los temas de las múltiples opciones que trabajan para proteger y garantizar los derechos de la demanda de la escuela.

Palabras clave

Política educativa; Violencia en las escuelas; Garantía de los derechos; Red de protección de derechos

Recebido em agosto, 2013

Aceite para publicação em outubro, 2013

i Centro de Teologia e Ciências Humanas, Pontifícia Universidade Católica do Paraná, Brasil

Toda a correspondência relativa a este artigo deve ser enviada para: Ana Maria Eyng, Rua Francisco Boscardin, 157, Código Postal 82.020-010, Bairro Cascatinha, Curitiba, Paraná, Brasil. E-mail: ana.eyng@pucpr.br 